\title{
Why Bother Asking? The Limited Value of Self- Reported Vote Intention
}

\section{Citation}

Rogers, Todd. 2012. Why Bother Asking? The Limited Value of Self-Reported Vote Intention. HKS Faculty Research Working Paper Series RWP12-001, John F. Kennedy School of Government, Harvard University

\section{Published Version}

http://web.hks.harvard.edu/publications/citation.aspx?Publd=8125

\section{Permanent link}

http://nrs.harvard.edu/urn-3:HUL.InstRepos:7779639

\section{Terms of Use}

This article was downloaded from Harvard University's DASH repository, and is made available under the terms and conditions applicable to Other Posted Material, as set forth at http:// nrs.harvard.edu/urn-3:HUL.InstRepos:dash.current.terms-of-use\#LAA

\section{Share Your Story}

The Harvard community has made this article openly available.

Please share how this access benefits you. Submit a story.

\section{Accessibility}




\section{Why Bother Asking? The Limited Value of Self-Reported Vote Intention Faculty Research Working Paper Series}

\section{Todd Rogers}

Harvard Kennedy School

Analyst Institute

Masa Aida

Greenberg Quinlan Rosner Research

\section{January 2012}

RWP12-001

The views expressed in the HKS Faculty Research Working Paper Series are those of the author(s) and do not necessarily reflect those of the John F. Kennedy School of Government or of Harvard University. Faculty Research Working Papers have not undergone formal review and approval. Such papers are included in this series to elicit feedback and to encourage debate on important public policy challenges. Copyright belongs to the author(s). Papers may be downloaded for personal use only. 
Why Bother Asking?

The Limited Value of Self-Reported Vote Intention

\author{
Todd Rogers ${ }^{1,2}$ and Masa Aida ${ }^{3}$ \\ ${ }^{1}$ Harvard Kennedy School, 79 John F. Kennedy Street, Cambridge, MA 02138 \\ ${ }^{2}$ Analyst Institute, 815 Sixteenth St NW, Washington, DC 20006 \\ ${ }^{3}$ Greenberg Quinlan Rosner Research, 10 G Street, NE, Suite 500, Washington, DC 20002 \\ [Currently Under Review] \\ (C) Todd Rogers
}

Acknowledgments: We would like to thank Greenberg Quinlan Rosner Research, Democracy Corps, AFL-CIO and an anonymous nonprofit for sharing their data with us. We would like to thank Debby Kermer for her help preparing this manuscript, and David Nickerson, Don Green, Mike Bailey, Ryan Enos and Dan Hopkins for their helpful feedback. 


\begin{abstract}
How accurate are people when predicting whether they will vote? These self-predictions are used by political scientists to proxy for political motivation, and by public opinion researcher to predict election outcomes. Phone surveys from three elections, including one survey experiment, are analyzed to compare respondents' pre-election vote intention with their actual voting behavior using administrative records $(\mathrm{N}=29,403)$. Unsurprisingly, many who predict that they will vote actually do not vote. More surprisingly, many who predict that they will not vote actually do vote (29\% to $56 \%$ ). Records of past voting behavior predicts turnout substantially better than self-prediction. Self-prediction inaccuracy is not caused by lack of cognitive salience of past voting, or by inability to recall past voting. Moreover, self-reported recall of turnout in one past election predicts future turnout just as well as self-prediction. We discuss implications for political science research, behavioral prediction, election administration policy, and public opinion.
\end{abstract}


People tend to over-estimate the likelihood that they performed a socially desirable behavior in the past (eg, whether they voted), and to over-estimate the likelihood that they will perform a socially desirable behavior in the future (Silver, Anderson, and Abramson 1986; Snyder 1974; Epley and Dunning 2000). Political scientists and public opinion researchers have wrestled with this problem for generations since both fields require accurate information about these kinds of behaviors: political scientists often use vote intention to understand the effects of other factors on political interest and engagement, while public opinion researchers often use vote intention to assess the distribution of preferences among those likely to vote. Despite its importance, the validity of answers to questions about respondents' intention to vote has been surprisingly understudied. In this manuscript we examine the accuracy of responses to questions about respondents' intentions to vote in an upcoming election, and find several surprising patterns. We analyze a unique collection of seven pre-election surveys with post-election vote validation, involving a total of 29,403 interviews appended to validated post-election public records of turnout. Five of these surveys were conducted during the 2008 US Presidential Election, one survey was conducted during the 2009 New Jersey General Election, and one survey experiment was conducted during the Wisconsin Recall Elections in 2011.

We report four findings of note. First, consistent with research on social desirability, in each election a meaningful fraction of those who say they will vote, do not. Second, in each election a surprising proportion of respondents who say they will not vote, in fact, do vote - a proportion that rivals the proportion who erroneously predict that they will vote but, in fact, do not vote. Third, past vote history is a much better predictor of turnout than self-reported intention to vote. In each election both forms of inaccurate self-prediction follow a similar pattern: people are more accurate when predicting they will behave consistently with their past 
behavior than when predicting they will behave inconsistently with their past behavior. That is, frequent voters are more accurate predicting that they will vote, whereas infrequent voters are more accurate predicting that they will not vote. Fourth, using a survey experiment we rule out two possible memory-based explanations for why respondents are so inaccurate at predicting their likelihood of voting, despite their past voting behavior being such a strong predictor of their future voting behavior. Respondents are not inaccurate because they do not have introspective access to accurate information in memory about their past vote history; and respondents are not inaccurate because their vote history is not cognitively salient at the time they are forming their self-predictions.

These findings enhance our understanding of when and why people will be (in)accurate in forecasting their future behavior, in general, and their future voting behavior, in particular. These findings cast doubt on the degree to which self-reported intention to vote questions predict actual future voting behavior, and on the degree to which they should be used to make inferences about respondents' political behaviors and motivations. Practically, these findings also shed light on a significant and previously unappreciated flaw in common likely-voter screens used to identify a probable electorate - the high rate of voting among people who report intending to not vote. In the discussion we probe the implications of these findings for political science research, the validity of behavioral prediction, design of policies relating to voter registration, and public opinion research. 


\section{LITERATURE REVIEW}

Intention to Vote as a Dependent Variable in Political Science.

Self-reported intention to vote has been a commonly used dependent variable as political scientists have attempted to understand the effects of other factors on political engagement. ${ }^{1}$ For example, the original research on the effects of negative advertising on political engagement used this question as its principal dependent variable to support the argument that "going negative" demotivates the electorate (Ansolabehere \& Iyengar 1995; Ansolabehere, Iyengar, \& Simon 1999; for a recent review, see Brooks 2006). Similarly, research on televised incivility used self-reported intention to vote to capture the consequences of combative television culture on political life (Mutz \& Reeves 2005). Research on the impact of campaign activities has used self-reported intention to vote to show the degree to which campaigns influence political engagement (Hillygus 2005). Work on how expectations about the participation of others affect political engagement have used self-reported intention to vote to show that citizens are more motivated to vote when they believe turnout will be relatively high as opposed to relatively low (Gerber \& Rogers 2009). Finally, recent research examining the impact of party affiliation on political behaviors found that inducing people to identify with a party made them more likely to intend to vote in an upcoming election (Gerber, Huber, \& Washington 2010). These examples highlight that self-reported intention to vote has been a commonly used dependent variable in political science research, which is one of the motivations for the present research.

\footnotetext{
${ }^{1}$ Psychologists also use questions involving intention to vote. For example, Fast and colleagues (2009) use intention to vote as a dependent variable to show the effects of increasing perceived power on general engagement.
} 


\section{Difficulties predicting turnout.}

Several papers have addressed the accuracy of turnout self-predictions, almost always focusing on identifying the optimal strategy for predicting turnout. Any review of this research must begin with Perry $(1960,1979)$ who wrestled with this problem extensively for The Gallup Organization. He developed several versions of a multiple-question battery to identify who would actually vote. The motivation for this research appears to have been eliminating those who were merely saying they would vote when, in fact, they would not. Of course, this is a sensible goal as it is common for respondents to say they intend to vote then not actually go and vote. However, this paper identifies reason for the opposite concern: respondents who predict they will not vote but then do so.

Several research teams have developed multiple-question batteries using the most recent ANES validated vote data, from 1980, 1984, and 1988 (Murray, Riley and Scime, 2009; Freedman and Goldstein, 1996). These datasets are relatively small compared to the datasets from which the current manuscript was developed which resulted in very few respondents volunteering some response options (ie, very few reported not intending to vote). Additionally, these datasets are from elections two to three decades ago as opposed to elections around which the current data were collected - the 2008 U.S. Presidential election, the 2009 New Jersey General Election, and the 2011 Wisconsin Recall elections.

The most recent election for which we were able to find a paper regarding errors in turnout prediction was the 2009 Philadelphia Municipal election. Dimock, Keeter, Schulman and Miller (2001) aimed to improve on Perry’s multiple-question batteries by considering new questions and different model specifications. Those authors matched the interviews of 1,694 
respondents to the municipal voter file, and were thus able to determine if a given respondent voted or not.

Dimock and colleagues (2011) asked two direct questions about the respondents' intentions to vote. First, they asked respondents if they planned to vote using a binary yes/no scale. Among respondents who could be matched to the voter file, $97 \%$ had reported that they planned to vote. The authors do not report the percentage who actually voted among the $3 \%$ of respondents who reported that they did not intend to vote. The second question measured intention to vote on a 10 -point scale, with 10 being the strongest intention, and 1 being the weakest intention. The authors reported that of the 1,694 respondents $7 \%$ offered an answer between 1 and 6 , and $39 \%$ of them actually voted. ${ }^{2}$ That such a substantial number of those who reported weak intentions to vote did, in fact, vote is striking. The research described in this manuscript builds on this finding.

\section{Prediction Errors}

There has been substantial research on errors in retrospective reporting of voter turnout, typically referred to as “over-reporting” (see Tourangeau, Rips, and Rainski, 2000; Silver, Abramson and Anderson, 1986). That work looks at how accurate respondents are at recalling whether or not they voted in the past. The present research explores people's beliefs about future behavior. While behavioral self-prediction is subtly different from behavioral intention, we view them as functionally similar: they are both an articulation of expectations regarding one's own future behavior. The Theory of Planned Behavior suggests that intentions about future behavior and actual future behaviors are more closely correlated when a person's attitude toward the

\footnotetext{
2 Mann (2003) finds a similar result but with a very small sample size: 27 respondents offer "less than 50-50" or "Definitely will not vote" and 7 actually did vote (26\%).
} 
behavior is positive (i.e., the person believes the behavior is desirable), when the person believes others think the behavior is desirable, and whether the person feels that performing the desired behavior is within her control (Ajzen, 1991). Voting is typically personally and socially desirable, as well as generally perceived as being within a person's control. This suggests that voting is exactly the kind of domain where the Theory of Planned Behavior would predict there to be strong correspondence between self-prediction and behavior. However, this is not what we find.

\section{STUDY 1}

\section{Dataset}

The dataset for Study 1 comes from five surveys using two types of sampling frames. The first dataset was collected for an anonymous client of Greenberg Quinlan Rosner Research. It used lists of registered voters with valid landline telephone numbers, provided by the voter file vendor Catalist, LLC. Catalist centralizes and maintains voter files from all states in the United States. This dataset included four surveys conducted over three months. The second dataset was collected for Democracy Corps, a $501 \mathrm{c}(4)$ independent non-profit research organization. It used random digit dialing (RDD) prescreened by Survey Sampling International for households with valid landline phones. This dataset included just one survey. The relevant portion of all surveys in Study 1 is the self-reported vote likelihood question.

\section{Survey}

Both datasets are based on interviews conducted by Greenberg Quinlan Rosner Research from all 50 states and the District of Columbia, with data collection stratified by region. All surveys were conducted by the same call center, with the same supervising staff and training procedure. Table 1 describes the combined dataset. 
All interviews included the same likely voter screen question asking respondents the following:

What are the chances of you voting in the election for president in November: are you almost certain to vote, will you probably vote, are the chances 50-50, or don't you think you will vote?

If the respondent answered "50-50", "will not vote" or volunteered that they "do not know", the interview was terminated. If the respondent answered "almost certain to vote" or "will probably vote", he or she was deemed to be a likely voter and the interview was continued. In these cases interviews generally lasted around twenty minutes. For calls to the RDD sample, respondents were asked their age, gender, and first name. For calls to the voter file sample, interviewers confirmed the name of the respondent. Thus, age, gender, first name, and phone number were available for all participants.

The proportion of respondents who refused to answer the likelihood of voting question and for whom we have data was quite small $(<1 \%)$. This group is excluded from subsequent analyses.

\section{Voting History}

Post-election, surveys were merged to the national voter file provided by Catalist, allowing us to study 2008 General Election vote history. Some states do not disclose individual vote histories, and some states did not release vote histories in time for the data analysis, therefore interviews from 39 states were included in the present analyses. ${ }^{3}$

For interviews completed using random-digit dial sampling (i.e, all Democracy Corps interviews) respondents were matched to the voter file using the phone number dialed,

\footnotetext{
${ }^{3}$ The 39 states included in the analysis are, AK, AL, AR, CO, DE, FL, GA, IA, ID, IL, IN, KS, KY, LA, MA, MD, ME, MI, MN, MO, MS, MT, NC, NH, NJ, NM, NV, NY, OH, OK, OR, PA, RI, SD, TN, UT, VT, WA, and WI.
} 
interviewer report of respondent's self-reported gender and age. Of these interviews, 54\%

matched the voter file using these criteria. For interviews completed calling from the voter file, respondents were matched after the election to the voter file using the name on the sample file, the phone number dialed, and interviewer report of respondents' self-reported gender and age. Of these interviews, 93\% matched the voter file using these criteria. Of 12,979 interviews with data collected for the intention to vote question, we matched 2008 General Election vote history to 11,025 interviews. All subsequent analyses reflect the data associated with only the interviews that matched the voter file.

Table 1. Matching Rates in Study 1

\begin{tabular}{|c|c|c|c|c|c|c|c|c|c|c|}
\hline \multirow[b]{2}{*}{ Date } & \multirow[b]{2}{*}{$\begin{array}{l}\text { Sample } \\
\text { Frame }\end{array}$} & \multirow{2}{*}{$\begin{array}{c}\# \text { answering } \\
\text { intention q } \\
(\mathrm{n}=12,979)\end{array}$} & \multirow{2}{*}{$\begin{array}{c}\text { Matched } \\
\text { cases } \\
(\mathrm{n}=11,025)\end{array}$} & \multicolumn{6}{|c|}{$\%$ Match to file } & \multirow{2}{*}{$\begin{array}{l}\text { Respons } \\
\text { e Rate* }\end{array}$} \\
\hline & & & & All & $\begin{array}{l}\text { Almost } \\
\text { certain }\end{array}$ & $\begin{array}{l}\text { Prob- } \\
\text { ably }\end{array}$ & $50-50$ & $\begin{array}{l}\text { Will } \\
\text { not }\end{array}$ & $\mid \begin{array}{l}{[\text { Don't }} \\
\text { Know }]\end{array}$ & \\
\hline $\begin{array}{c}6 / 18 / 200 \\
8 \\
\end{array}$ & $\begin{array}{l}\text { Voter } \\
\text { File } \\
\end{array}$ & 3,444 & 3,205 & $93 \%$ & $93 \%$ & $94 \%$ & $97 \%$ & $98 \%$ & $98 \%$ & $1.94 \%$ \\
\hline $\begin{array}{c}7 / 24 / 200 \\
8 \\
\end{array}$ & $\begin{array}{l}\text { Voter } \\
\text { File } \\
\end{array}$ & 3,937 & 3,699 & $94 \%$ & $94 \%$ & $92 \%$ & $92 \%$ & $93 \%$ & $98 \%$ & $2.46 \%$ \\
\hline $\begin{array}{c}8 / 24 / 200 \\
8\end{array}$ & $\begin{array}{l}\text { Voter } \\
\text { File }\end{array}$ & 1,612 & 1,443 & $90 \%$ & $90 \%$ & $90 \%$ & $88 \%$ & $100 \%$ & $\begin{array}{c}100 \\
\%\end{array}$ & $1.78 \%$ \\
\hline $\begin{array}{c}9 / 16 / 200 \\
8\end{array}$ & $\begin{array}{l}\text { Voter } \\
\text { File }\end{array}$ & 1,833 & 1,623 & $89 \%$ & $89 \%$ & $83 \%$ & $92 \%$ & $76 \%$ & $76 \%$ & $1.81 \%$ \\
\hline $\begin{array}{c}10 / 24 / 20 \\
08\end{array}$ & RDD & 2,153 & 1,055 & $49 \%$ & $49 \%$ & $47 \%$ & $43 \%$ & $37 \%$ & $48 \%$ & $1.99 \%$ \\
\hline
\end{tabular}

* AAPOR Response Rate 2 reflects all responses for which the turnout question is collected in the numerator, and all phone numbers initially scheduled to be called in the denominator. Research has found that non-response can be unrelated to survey bias (Merkle \& Edelman, 2002).

\section{Self-Prediction Accuracy}

In the following we sometimes display our findings in terms of self-prediction “accuracy." We define an accurate self-prediction as when a respondent who reported that she 
was "almost certain to vote" actually voted, and when a respondent who reported that she "will not vote" actually did not vote. For discussions of accuracy we exclude those who responded that they would "probably vote" and that they had a "50-50" chance of voting because it is not obvious what it would mean for these to be accurate predictions. It is common for practitioners to force these four response options into two categories, those in the likely electorate (those offering "almost certain to vote" and "probably vote") and those not in the likely electorate (those offering "50-50" and "will not vote"). Indeed, this is how the original researchers determined which respondents to terminate and which to continue the interview with. We also report the raw percentage of respondents from each response category who actually voted regardless of their prediction accuracy.

\section{Results}

Table 2 compares self-reported likelihood of voting in the 2008 General Election with actual turnout records. A cursory glance reveals three patterns of note. First, $54.8 \%$ of those who report that they will not vote, in fact, do vote. Second, $13.3 \%$ of those who reported being almost certain to vote did not vote. This is consistent with social desirability bias research, according to which people may have knowingly reported false intentions, but could also result from unanticipated obstacles preventing respondents from voting despite their otherwise genuine intention. Third, we find that the percentage of those who voted despite predicting that they would not $(54.8 \%)$ is significantly larger than the percentage of those who did not vote despite predicting that they would $(13.3 \%),\left(\chi^{2}(1, N=9473)=277.5, \mathrm{p}<.001\right)$. 
Table 2. Study 1 Likelihood of Voting and Actual Turnout

\begin{tabular}{|c|l|c|c|c|}
\hline \multirow{2}{*}{} & \multicolumn{2}{|c|}{ Actually vote? } & \multirow{2}{*}{ Total N } \\
\cline { 3 - 5 } & & Yes & No & Totan \\
\hline \multirow{3}{*}{$\begin{array}{c}\text { Self-Reported } \\
\text { Likelihood to Vote }\end{array}$} & Almost Certain & $87 \%$ & $13 \%$ & 9,272 \\
\cline { 2 - 5 } & Probably & $74 \%$ & $26 \%$ & 1,004 \\
\cline { 2 - 5 } & $50-50$ & $67 \%$ & $33 \%$ & 417 \\
\cline { 2 - 5 } & Will not vote & $55 \%$ & $45 \%$ & 201 \\
\cline { 2 - 5 } & [Don't know] & $76 \%$ & $24 \%$ & 131 \\
\hline
\end{tabular}

The question asked was: What are the chances of you voting in the election for president in November: are you almost certain to vote, will you probably vote, are the chances 50-50, or don't you think you will vote?

Note: We cannot prove that a respondent did not vote. We report here that the Secretary of State of the state in which a given respondent lives does not indicate the respondent had cast a vote. 
Temporal Distance and Accuracy of Prediction. Were self-reported likelihoods of voting more accurate as the election approached? One might suspect that as Election Day neared respondents might have had introspective access to information useful to predicting their future behavior. Table 3 shows turnout rate for each response option as a function of when the interview occurred. If respondents gained insight into their likely voting behavior as the election approached, we would hypothesize that errors in turnout predictions would decrease as Election Day approached. This was not confirmed, as there appears to be no trend in accuracy $(r(10,894)$ $=.012, \mathrm{p}=.21)$. This suggests that the inaccuracy of this self-reported vote likelihood question is not caused by failure to anticipate enthusiasm about the 2008 General Election as Election Day neared.

Table 3. Study 1 Actual Turnout by Self-Predicted Turnout Over Time

\begin{tabular}{|c|c|c|c|c|c|c|}
\hline & & June & July & August & September & October \\
\hline \multirow{5}{*}{$\begin{array}{c}\text { Self- } \\
\text { Reported } \\
\text { Likelihood } \\
\text { to Vote }\end{array}$} & $\begin{array}{l}\text { Almost } \\
\text { Certain }\end{array}$ & $\begin{array}{c}91 \% \\
(n=2,675) \\
\end{array}$ & $\begin{array}{c}80 \% \\
(n=3,061) \\
\end{array}$ & $\begin{array}{c}89 \% \\
(n=1,210) \\
\end{array}$ & $\begin{array}{c}89 \% \\
(n=1,423) \\
\end{array}$ & $\begin{array}{c}90 \% \\
(n=903)\end{array}$ \\
\hline & Probably & $\begin{array}{c}85 \% \\
(n=305)\end{array}$ & $\begin{array}{c}67 \% \\
(n=366)\end{array}$ & $\begin{array}{c}78 \% \\
(n=138)\end{array}$ & $\begin{array}{c}68 \% \\
(n=115)\end{array}$ & $\begin{array}{c}73 \% \\
(n=80)\end{array}$ \\
\hline & $50-50$ & $\begin{array}{c}70 \% \\
(n=126) \\
\end{array}$ & $\begin{array}{c}64 \% \\
(n=151) \\
\end{array}$ & $\begin{array}{c}64 \% \\
(n=53) \\
\end{array}$ & $\begin{array}{c}63 \% \\
(n=48) \\
\end{array}$ & $\begin{array}{c}74 \% \\
(n=39) \\
\end{array}$ \\
\hline & Will not vote & $\begin{array}{c}68 \% \\
(n=60)\end{array}$ & $\begin{array}{c}48 \% \\
(n=69)\end{array}$ & $\begin{array}{c}43 \% \\
(n=28)\end{array}$ & $\begin{array}{c}48 \% \\
(n=21)\end{array}$ & $\begin{array}{c}61 \% \\
(n=23)\end{array}$ \\
\hline & [Don't know] & $\begin{array}{c}82 \% \\
(n=39)\end{array}$ & $\begin{array}{c}75 \% \\
(n=52)\end{array}$ & $\begin{array}{c}64 \% \\
(n=14)\end{array}$ & $\begin{array}{c}75 \% \\
(n=16)\end{array}$ & $\begin{array}{c}80 \% \\
(n=10)\end{array}$ \\
\hline
\end{tabular}

Past Behavior. Psychological research has consistently shown that one of the best predictors of future behavior is past behavior (Triandis 1977; Ouellette and Wood 1998), which prompts the question: how does past vote history relate to the accuracy of respondents' vote 
likelihood predictions? To examine this relationship we looked at how many of the prior two General Elections (2004 and 2006) each respondent voted in, as reported by the voter file. The analyses below include those who were ineligible to vote in the prior two General Elections due to their age. Excluding those citizens does not substantively affect the results. Table 4 reports the turnout rate among those who had voted in zero, one, or two of the prior two General Elections.

Table 4. Study 1 Actual Turnout by Self-Predicted Turnout by Vote History

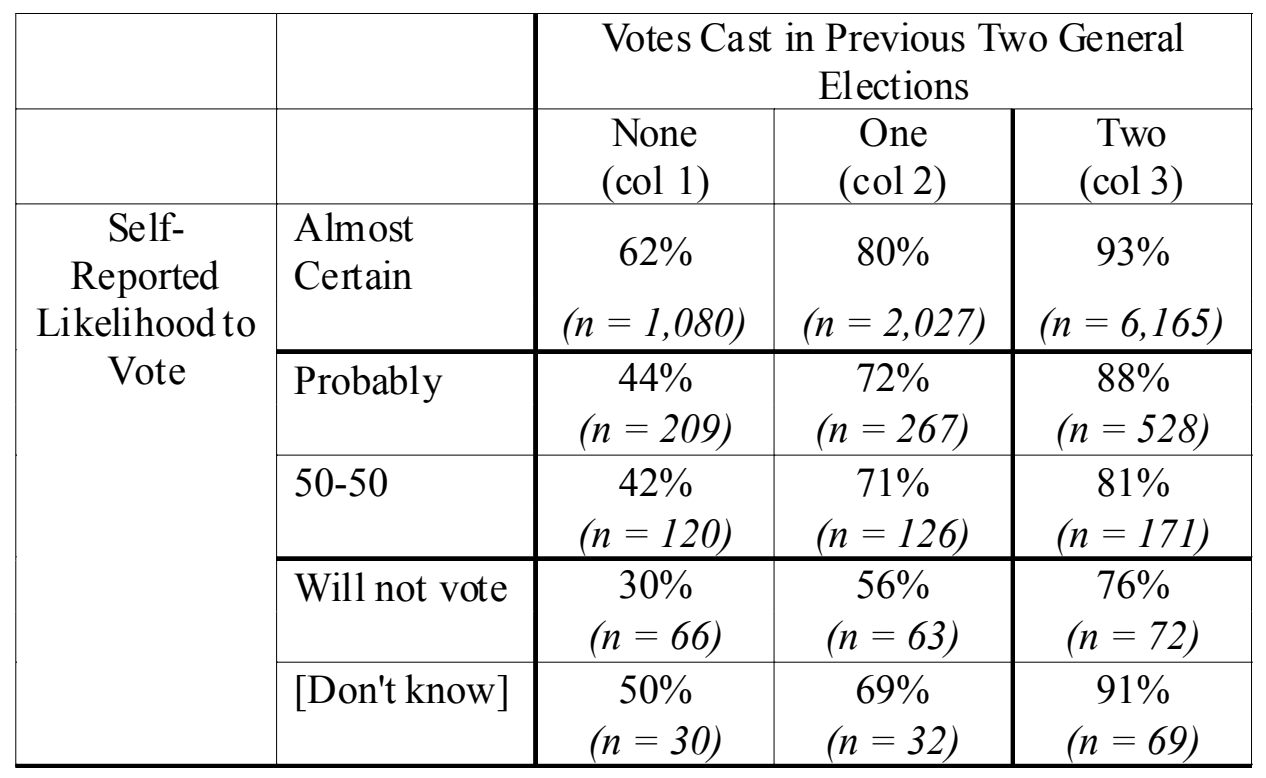

Figure 1 plots the accuracy of respondents' turnout self-predictions crossed with their recent vote history. For simplicity of presentation, this figure only includes the two extreme response options. Respondents who offered that they are "almost certain to vote" would have made accurate self-predictions when they actually did vote in the current election. Respondents who offered that they "will not vote" would have made accurate self-predictions when they actually did not vote in the current election. Table 4 and Figure 1 show that people are more 
accurate when their self-predictions were consistent with their past voting behavior. Specifically, respondents who had voted in the past two General Elections (column 3 in Table 4) were more accurate when predicting that they "were almost certain to vote" (93\% of those predicting that they "were almost certain to vote" actually did vote; $93 \%$ accuracy since accurate prediction for this response option entailed actually casting a vote) than that they "will not vote" (76\% of those predicting that they "will not vote" actually did vote; $24 \%$ accuracy since accurate prediction for this response option entailed not casting a vote). Similarly, respondents who had voted in zero of the prior two General Elections (column 1 in Table 4) were more accurate at predicting that they "will not vote" (30\% of those predicting that they "will not vote" actually did vote; $70 \%$ accuracy since accurate prediction for this response option entailed not casting a vote) than that they were "almost certain to vote" (62\% of those predicting that they were "almost certain to vote" actually did vote; $62 \%$ accuracy since accurate prediction for this response option entailed actually casting a vote). A logistic regression shows that the interaction between vote history and predictions on accuracy is statistically significant (odds ratio $=.12, \mathrm{p}<.001$ ).

To compare the explanatory power of the turnout self-prediction question to that of past vote history, we used a series of ordinary least squares models with age and gender as additional covariates. Including self-predicted likelihood alone explained $4.0 \%$ of variance whereas including past vote history alone explained $10.3 \%$ of variance. The model with both selfprediction and past vote history explained $11.9 \%$ of the variance. ${ }^{4}$

\footnotetext{
${ }^{4}$ Entering each level of response to the self-prediction question as a dummy variable instead of as a continuous variable does not substantially change the results: including self-predicted likelihood alone explained $4.0 \%$ of variance whereas including past vote history alone explained $10.4 \%$ of variance. The model with both selfprediction and past vote history explained $12.0 \%$ of the variance.
} 
Figure 1. Study 1 Respondents Are More Accurate When Predicting Past-Consistent Behavior

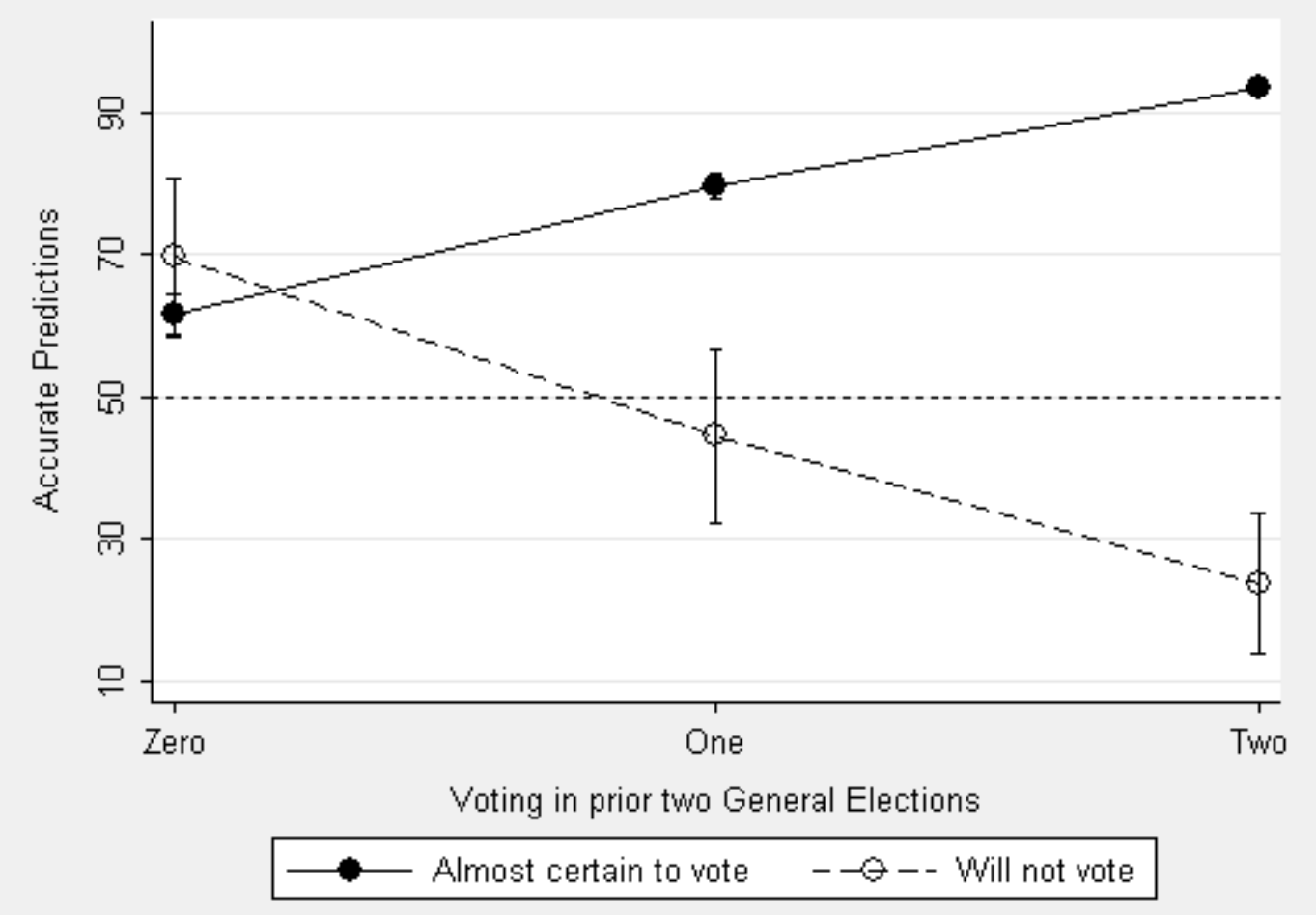

Accuracy refers to the percentage of respondents who actually voted after predicting "almost certain to vote" (solid line) and who did not vote after predicting "will not vote" (dashed line). Error bars indicate 95\% confidence interval.

\section{Discussion}

In Study 1, not only did high percentages of those who predicted that they would not vote actually vote $(54.7 \%)$, but this was greater than the percentage of those predicting that they would vote who did not (13.3\%). Accuracy was unrelated to time before the election, but was significantly affected by consistency with voting in recent similar elections. Specifically, accuracy was greatest when predictions were consistent with past behavior. 
Since the 2008 General Election had unusually high interest and turnout, Study 2 examines the same questions in a different less prominent election, the 2009 NJ General Election.

\section{STUDY 2}

\section{Dataset}

The dataset for Study 2 comes from a survey of New Jersey citizens prior to the 2009 NJ General Election. These calls were not conducted with this research in mind, and was instead conducted on behalf of an anonymous $501 \mathrm{c}(4)$ organization that supports nonpartisan voter registration and GOTV efforts. Participants were randomly selected from a list of registered voters with unique, valid phone numbers who met three additional criteria: 1) Were African American or Hispanic, 2) Had voted in the 2008 General Election, 3) did not vote in the 2006 General Election. Those who had already voted in the target election by the time of the interviews were also excluded.

\section{Survey}

Callers from a paid phone center introduced themselves and stated that the purpose of the call was to encourage the targets to vote. They then asked the respondent "Do you plan to [vote/be a voter] on Tuesday?" There were two variants of the self-prediction question as part of an unrelated experiment. The wording of this question did not affect the results reported in the present analysis, and so all analyses report the combined data. The response options were simply "Yes" or "No." The calls continued as part of the unrelated experiment. 13,278 responded to the vote prediction question. 
Table 5. Study 2 Likelihood of Voting and Actual Tumout

\begin{tabular}{|c|c|c|c|c|}
\hline & \multicolumn{2}{|c|}{ Actually vote? } & \multirow{2}{*}{$\begin{array}{c}\text { Total } \\
\mathrm{N}\end{array}$} \\
\hline & & Yes & No & \\
\hline \multirow{3}{*}{$\begin{array}{c}\text { Self-Reported } \\
\text { Likelihood to } \\
\text { Vote }\end{array}$} & Yes & $45.8 \%$ & $54.2 \%$ & 8,810 \\
\hline & No & $29.3 \%$ & $70.7 \%$ & 3,150 \\
\hline & [Don't know] & $42.4 \%$ & $57.6 \%$ & 1,318 \\
\hline & Total & $41.5 \%$ & $58.5 \%$ & 13,278 \\
\hline
\end{tabular}

The question asked was: Do you plan to [be a voter/vote] on Tuesday?

Note: We cannot prove that a respondent did not vote. We report here that the Secretary of State of NJ does not indicate the respondent cast a vote. AAPOR Response Rate 2 was $30.2 \%$

Voting History

After the election, respondent data was merged with the voter file provided by Catalist, allowing access to vote history for the 2009 NJ General Election and prior elections. Since the initial participant list was drawn from the provided voter file and callers were instructed to talk only to the target, the ID allowed for complete matching.

Results

Table 5 compares self-reported likelihood to vote in the 2009 New Jersey General Election with actual turnout records. In comparison to turnout for the 2008 General election as discussed in Study 1, overall voting rates were much lower. Less than half of registered New Jersey voters cast a ballot in the 2009 New Jersey General Election, compared to over 84 percent in 2008. Nonetheless, results were consistent with two of the hypotheses. First, 29.3 percent of those who report that they would not vote, in fact, did vote. Second, although 45.8 percent of those who said they would vote did, 54.2 percent did not. 
Past Behavior. In Study 1, respondents gave more accurate predictions about voting in the upcoming general election if the prediction was consistent with their past vote history. Study 2 occurred during a gubernatorial General Election, so we looked at whether each respondent had voted in the prior two elections for statewide office (2005 and 2007). Table 6 reports the turnout rate among those who had voted in zero, one, or two of those elections.

Table 6. Study 2 Turnout by Self-Reported Likelihood and Past Voting Behavior

\begin{tabular}{|c|c|c|c|c|}
\hline & \multicolumn{3}{|c|}{ Voting in prior two state elections } \\
\hline & & $\begin{array}{l}\text { None } \\
(\operatorname{col} 1)\end{array}$ & $\begin{array}{l}\text { One } \\
(\operatorname{col} 1)\end{array}$ & $\begin{array}{l}\text { Two } \\
(\operatorname{col} 1)\end{array}$ \\
\hline \multirow{3}{*}{$\begin{array}{l}\text { Self-Reported } \\
\text { Likelihood } \\
\text { to Vote }\end{array}$} & Yes & $\begin{array}{c}39 \% \\
(n=6,470)\end{array}$ & $\begin{array}{c}60 \% \\
(n=1,803)\end{array}$ & $\begin{array}{c}80 \% \\
(n=525)\end{array}$ \\
\hline & No & $\begin{array}{c}24 \% \\
(n=2,505)\end{array}$ & $\begin{array}{c}48 \% \\
(n=521)\end{array}$ & $\begin{array}{c}66 \% \\
(n=123)\end{array}$ \\
\hline & Don't Know & $\begin{array}{c}35 \% \\
(n=985)\end{array}$ & $\begin{array}{c}62 \% \\
(n=257)\end{array}$ & $\begin{array}{c}76 \% \\
(n=76)\end{array}$ \\
\hline
\end{tabular}

Figure 2 plots accuracy of respondents' self-predictions, illustrating that respondents were again more accurate when their self-predictions were consistent with their past voting behavior, and vice versa. Specifically, respondents who had voted two of the past two New Jersey General Elections (column 3 in Table 6) were more accurate when predicting that they would vote (80\% of those predicting that they would vote actually did vote; $80 \%$ accuracy since accurate prediction for this response option entailed actually casting a vote) than that they would not vote (66\% of those predicting that they would not vote actually did vote; $34 \%$ accuracy since accurate prediction for this response option entailed not casting a vote). Similarly, respondents who had voted in zero of the past two New Jersey General Elections (column 1 in Table 6) were more accurate at predicting that they would not vote $(24 \%$ of those predicting that they would not vote actually did vote; $76 \%$ accuracy since accurate prediction for this response option entailed not 
casting a vote) than that they would vote ( $39 \%$ of those predicting that they would vote actually did vote; $39 \%$ accuracy since accurate prediction for this response option entailed actually casting a vote). A logistic regression shows that the interaction between vote history and predictions on accuracy is statistically significant (odds ratio $=.6 .71, \mathrm{p}<.001$ ).

To compare the explanatory power of the turnout self-prediction question to that of vote history we used a series of ordinary least squares models with age and gender as additional covariates. Including self-predicted likelihood alone explained $4.6 \%$ of variance whereas including past vote history alone explained $7.4 \%$ of variance. The model with both selfprediction and past vote history explained $9.1 \%$ of the variance. ${ }^{5}$

\footnotetext{
${ }^{5}$ Entering each level of response to the self-prediction question as a dummy variable instead of as a continuous variable does not substantially change the results: including self-predicted likelihood alone explained $4.9 \%$ of variance whereas including past vote history alone explained $7.8 \%$ of variance. The model with both self-prediction and past vote history explained $9.3 \%$ of the variance.
} 
Figure 2. Study 2 Respondents Are More Accurate When Predicting Past-Consistent Behavior

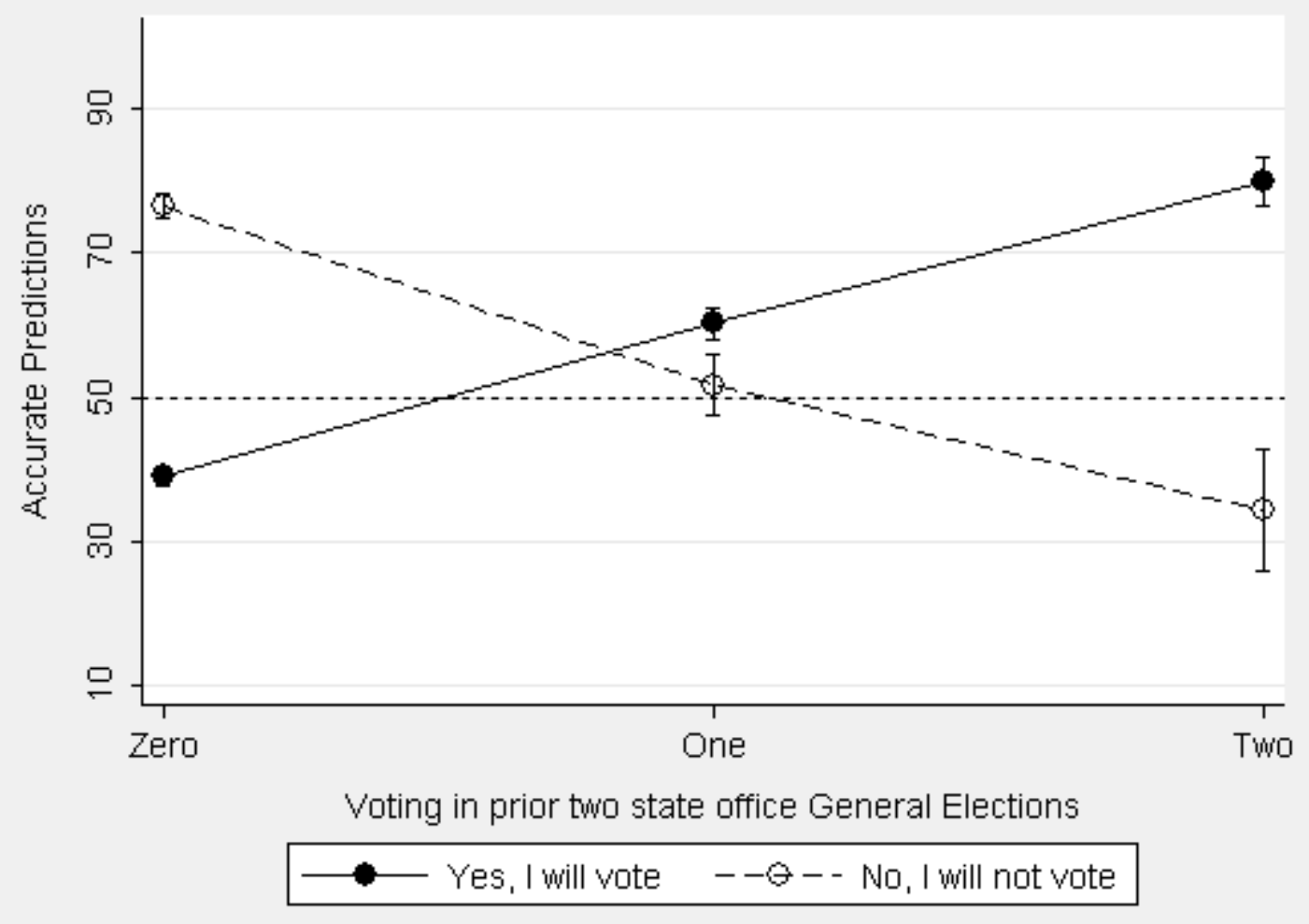

Accuracy refers to the percentage of respondents who actually voted after predicting that they would vote (solid lines) and who did not vote after predicting that they would vote (dashed lines). Error bars indicate 95\% confidence interval.

\section{Discussion}

Whereas Study 1 examines data from an election with very high turnout, Study 2 examines data from an election with substantially lower turnout. In fact, although two-thirds of those called reported intending to vote, less than half actually did. Consequently, accuracy was greatest among those who said they did not plan to vote. But, as in Study 1, a substantial percentage of those who predicted they would not vote actually did (29\%). Further, over half of those who predicted they would vote (54\%) did not. Another pattern discovered in Study 1 
emerged in Study 2 as well: accuracy was greatest when predictions were consistent with past voting behavior. 


\section{STUDY 3}

In Study 3 we examine two possible memory-based mechanisms for why people are so inaccurate at predicting their future voting likelihood. First, we examine if people simply do not have introspective access to accurate information in memory about whether they voted in a previous similar election. The poor prediction accuracy shown in the previous two studies could be partly explained if we find that people simply do not have access to accurate information in memory about their past behavior. Second, we examine if prediction accuracy can be improved by making more cognitively salient accurate information in memory about past behavior from a recent similar election. In Study 3 we also attempt to replicate the patterns of inaccurate selfprediction found in Study 1 and Study 2 in another election context.

\section{Dataset}

The dataset for Study 3 comes from a survey of Wisconsin citizens conducted prior to the 2011 State Senate Recall Elections in July and August, 2011. These interviews were conducted for the AFL-CIO and not principally for this research. The objective of the interviews was to help the AFL-CIO build microtargeting models to identify which citizens would support which candidates. Participants were randomly selected from a list of registered voters with unique, valid phone numbers.

\section{Survey}

Callers from a paid phone center introduced themselves and stated that the purpose of the call was to ask questions about the upcoming election. All respondents were answered two key questions, and were randomly assigned to which one they answered first. Those assigned to Recall-First were asked to recall whether they had voted in a Supreme Court election held the 
Why Bother Asking? 24

previous April. This was the most recent previous election that was expected to have similar turnout to that of the forthcoming recall election. They were asked "There was an election for Supreme Court held on April 5 of this year. Were you able to make it to the polls and vote in this election?" The response options were voted, did not vote, or don’t know/refused. Those assigned to Intention-First were asked about their intention to vote in the upcoming election. They were asked "As you may have heard, there will be an election to recall [INCUMBENT PARTY] state senator [INCUMBENT NAME]. Do you intend to vote in this upcoming election?" The coded response options were definitely, probably, 50/50, will not vote, and don't know/refused. 5,100 respondents answered both questions. We had the same interview rate across conditions, and they do not significantly differ on demographic variables available on the file such as gender, age, percent Democrat, percent Republican, or turnout in April Supreme Court vote history (all $p \mathrm{~s}>.10$ ). All subsequent analyses include only respondents who answered both questions.

\section{Voting History}

After the election, respondent data was merged with the voter file provided by Catalist, LLC, allowing access to vote history for the 2011 WI Recall Election and prior elections. Since the initial participant list was drawn from the provided voter file and callers were instructed to talk only to the target, all respondents were matched to the post-election validated voter file.

\section{Results}

Recall Accuracy. The first question we were interested in was whether respondents had introspective access to whether or not they voted in the previous election that was most similar to the upcoming election. We find that $80.1 \%$ of respondents correctly recalled whether or not they 
had voted in the April 2011 Supreme Court elections. Among those who said that they did vote in the target election $(n=3,743), 79.3 \%$ actually did vote $(20.7 \%$ did not $)$. Among those who said that they did not vote in the target election $(n=1,257), 84.9 \%$ actually did not vote $(15.1 \%$ did vote). Among those who say they did not know or refused to answer the question $(n=100)$, $53.0 \%$ actually did vote $(47.0 \%$ did not). Accuracy was not affected by whether the respondent was in Recall-First or Predict-First $(\mathrm{X} 2=.01, p>.9)$. This data suggests that respondents have access to reasonably accurate information regarding their past vote history, given the motivational biases people have to over-report their vote history (Tourangeau 2000; Silver, Anderson, and Abramson 1986), as well as the cognitive challenges of accurately remembering past experiences (Schacter 1999).

Effect of Recall on Prediction Accuracy. We had to create a criterion for what constituted an accurate turnout prediction in order to assess the impact of asking respondents to recall their past turnout before predicting their future turnout. Since the turnout prediction question had five response options, we used the response option indicating the greatest degree of certainty that one would vote ("I will definitely vote") as a prediction that one would vote. We used the response option indicating the greatest degree of certainty that one would not vote ("I will not vote") as a prediction that one would not vote. The relationship between all other prediction options and actual turnout is not incorporated into our measure of prediction accuracy. Among those in Recall-First condition, $80.4 \%$ correctly predicted whether or not they would vote. Among those in the Prediction-First condition, $80.3 \%$ correctly predicted whether or not they would vote. Table 7 shows turnout associated with each response option, with panels for each of the two question-order conditions. 
Table 7 Study 3 Turnout by Self-Reported Likelihood to Vote and Recall of Past Voting

\begin{tabular}{|c|c|c|c|c|c|c|c|}
\hline & & \multicolumn{2}{|c|}{$\begin{array}{l}\text { Recall-First } \\
(\text { col 1) }\end{array}$} & \multicolumn{2}{|c|}{$\begin{array}{l}\text { Prediction-First } \\
(\operatorname{col} 2)\end{array}$} & \multicolumn{2}{|c|}{$\begin{array}{l}\text { All Respondents } \\
(\operatorname{col} 3)\end{array}$} \\
\hline & & Voted & $\begin{array}{l}\text { Did not } \\
\text { vote }\end{array}$ & Voted & $\begin{array}{l}\text { Did not } \\
\text { vote }\end{array}$ & Voted & $\begin{array}{l}\text { Did not } \\
\text { vote }\end{array}$ \\
\hline \multirow{5}{*}{$\begin{array}{c}\text { Self- } \\
\text { Reported } \\
\text { Likelihood } \\
\text { to Vote }\end{array}$} & $\begin{array}{l}\text { Definitely } \\
\text { will vote }\end{array}$ & $\begin{array}{c}83.1 \% \\
(n=1,670)\end{array}$ & $\begin{array}{c}16.9 \% \\
(n=339)\end{array}$ & $\begin{array}{c}82.3 \% \\
(n=1,655)\end{array}$ & $\begin{array}{c}17.7 \% \\
(n=357)\end{array}$ & $\begin{array}{c}82.7 \% \\
(n=3,325)\end{array}$ & $\begin{array}{c}17.3 \% \\
(n=696)\end{array}$ \\
\hline & $\begin{array}{l}\text { Probably } \\
\text { will vote }\end{array}$ & $\begin{array}{c}61.6 \% \\
(n=69) \\
\end{array}$ & $\begin{array}{c}38.4 \% \\
(n=43) \\
\end{array}$ & $\begin{array}{c}58.2 \% \\
(n=99) \\
\end{array}$ & $\begin{array}{c}41.8 \% \\
(n=71) \\
\end{array}$ & $\begin{array}{c}59.6 \% \\
(n=168) \\
\end{array}$ & $\begin{array}{c}40.4 \% \\
(n=114) \\
\end{array}$ \\
\hline & $50-50$ & $\begin{array}{c}48.7 \% \\
(n=58)\end{array}$ & $\begin{array}{c}51.3 \% \\
(n=61)\end{array}$ & $\begin{array}{c}41.6 \% \\
(n=47)\end{array}$ & $\begin{array}{c}58.4 \% \\
(n=66)\end{array}$ & $\begin{array}{c}45.3 \% \\
(n=105)\end{array}$ & $\begin{array}{c}54.7 \% \\
(n=127)\end{array}$ \\
\hline & $\begin{array}{l}\text { Will not } \\
\text { vote }\end{array}$ & $\begin{array}{c}42.9 \% \\
(n=105)\end{array}$ & $\begin{array}{c}57.1 \% \\
(n=140)\end{array}$ & $\begin{array}{c}36.0 \% \\
(n=82)\end{array}$ & $\begin{array}{c}64.0 \% \\
(n=146)\end{array}$ & $\begin{array}{c}39.5 \% \\
(n=187)\end{array}$ & $\begin{array}{c}60.5 \% \\
(n=286)\end{array}$ \\
\hline & $\begin{array}{l}\text { DK/ } \\
\text { Refused }\end{array}$ & $\begin{array}{c}59.6 \% \\
(n=28)\end{array}$ & $\begin{array}{c}40.4 \% \\
(n=19)\end{array}$ & $\begin{array}{c}42.2 \% \\
(n=19)\end{array}$ & $\begin{array}{c}57.8 \% \\
(n=26)\end{array}$ & $\begin{array}{c}51.1 \% \\
(n=47)\end{array}$ & $\begin{array}{c}48.9 \% \\
(n=45)\end{array}$ \\
\hline
\end{tabular}

The question asked was: As you may have heard, there will be an election to recall [INC_PART] state senator [INC_NAME]. Do you intend to vote in this upcoming election?

Note: We cannot prove that a respondent did not vote. We report here that the Secretary of State of WI does not indicate the respondent cast a vote.

AAPOR Response Rate 2 was $9.0 \%$

Since question order did not affect accuracy of past vote recall, we are able to compare the prediction accuracy of those for whom accurate past behavior from a recent similar election was made salient before they predicted their voting likelihood (those who accurately recalled their past voting behavior in the Recall-First condition) to those for whom that information was not made salient before predicting whether or not they will vote (those who accurately recalled their past voting behavior in the Predict-First condition). Among those who accurately recalled their past vote history, making past vote history salient before predicting future turnout did not improve respondents' prediction accuracy, $\mathrm{X} 2(1)=0.020, \mathrm{p}=.888$. Among all respondents, 
recalling their vote history before predicting their future turnout slightly (but inconsequentially) changed respondents' turnout predictions, X2 $(4,5100)=12.49, p=.014$. In the Recall-First condition, 1.0 percentage point more respondents predicted they would definitely vote (79.3\%) compared to those in the Predict-First (78.3\%). When dichotomizing the respondents into those who predicted they would definitely vote and all others, we find recalling vote history does not affect prediction accuracy, X2 $(1,5100)=0.01, p=.90$.

Table 7 shows self-reported likelihood to vote in the 2011 Wisconsin Recall Election with actual turnout records. Results were consistent with the previous two studies. First, 39.5 percent of all respondents who report that they would not vote, in fact, did vote. Second, although 82.7 percent of all respondents who said they would vote did, 17.3 percent did not. 
Past Behavior. In Study 1 and Study 2, respondents gave more accurate predictions about voting in the upcoming general election if the prediction was consistent with their past vote history. In both of those studies we looked at whether each respondent had voted in the prior two comparable elections. Study 3 occurred in a highly unusual recall election context. The two most comparable elections preceding this election were the April, 2011, Supreme Court election and the February, 2008, Presidential Primary. Table 8 reports the turnout rate among respondents who had voted in zero, one, or two of those elections. ${ }^{6}$

Table 8. Study 3 Actual Turnout by Self-Predicted Turnout by Vote History

\begin{tabular}{|c|c|c|c|c|}
\hline \multirow{4}{*}{} & & \multicolumn{3}{|c|}{$\begin{array}{c}\text { Votes Cast in Previous Comparable } \\
\text { Wisconsin Elections }\end{array}$} \\
\hline \multirow{4}{*}{$\begin{array}{c}\text { Self- } \\
\text { Reported } \\
\text { Likelihood to } \\
\text { Vote }\end{array}$} & $\begin{array}{c}\text { Done } \\
(\text { col 1) }\end{array}$ & $\begin{array}{c}\text { One } \\
(\mathrm{col} 2)\end{array}$ & $\begin{array}{c}\text { Two } \\
(\mathrm{col} 3)\end{array}$ \\
\cline { 2 - 5 } & Prill vote & $\begin{array}{c}51.6 \% \\
(n=504)\end{array}$ & $\begin{array}{c}78.3 \% \\
(n=1197)\end{array}$ & $\begin{array}{c}91.7 \% \\
(n=2320)\end{array}$ \\
\cline { 2 - 6 } & Probably & $\begin{array}{c}27.5 \% \\
(n=80)\end{array}$ & $\begin{array}{c}62.1 \% \\
(n=116)\end{array}$ & $\begin{array}{c}86.0 \% \\
(n=86)\end{array}$ \\
\cline { 2 - 6 } & Will vote & $\begin{array}{c}26.1 \% \\
(n=88)\end{array}$ & $\begin{array}{c}45.1 \% \\
(n=82)\end{array}$ & $\begin{array}{c}72.6 \% \\
(n=62)\end{array}$ \\
\cline { 2 - 6 } & Will not vote & $\begin{array}{c}14.7 \% \\
(n=211)\end{array}$ & $\begin{array}{c}43.7 \% \\
(n=151)\end{array}$ & $\begin{array}{c}81.1 \% \\
(n=111)\end{array}$ \\
\cline { 2 - 6 } & [Don't know $]$ & $\begin{array}{c}20.7 \% \\
(n=29)\end{array}$ & $\begin{array}{c}60.0 \% \\
(n=35)\end{array}$ & $\begin{array}{c}71.4 \% \\
(n=28)\end{array}$ \\
\hline
\end{tabular}

\footnotetext{
${ }^{6}$ Table 8 shows actual turnout by vote history in the past two comparable elections because this is the format of the data shown in Study 1 and Study 2. In the survey experiment in Study 3 we only asked respondents to recall whether or not they voted in the single most recent similar election, the April Supreme Court election. The same pattern holds when examining this data where vote history includes only None and One votes cast. For example, among those who did vote in the April election, $90 \%$ of those who self-reported that they "definitely will vote" actually voted, while $76 \%$ of those who reported that they "will not vote" actually voted. Conversely, among those who did not vote in the April election, $61 \%$ of those who self-reported that they "definitely will vote" actually voted, while $20 \%$ of those who reported that they "will not vote" actually voted.
} 
Figure 3 plots accuracy of respondents' self-predictions, illustrating that respondents were again more accurate when their self-predictions were consistent with their past voting behavior, and vice versa. Specifically, respondents who had voted in both of the most comparable past elections in Wisconsin (column 3 in Table 8) were more accurate when predicting that they would vote $(91.7 \%$ of those predicting that they would vote actually did vote; $91.7 \%$ accuracy since accurate prediction for this response option entailed actually casting a vote) than that they would not vote $(81.1 \%$ of those predicting that they would not vote actually did vote; $18.9 \%$ accuracy since accurate prediction for this response option entailed not casting a vote). Similarly, respondents who had voted in zero of the most comparable past elections in Wisconsin (column 1 in Table 8$)$ were more accurate at predicting that they would not vote $(14.7 \%$ of those predicting that they would not vote actually did vote; $85.3 \%$ accuracy since accurate prediction for this response option entailed not casting a vote) than that they would vote $(51.6 \%$ of those predicting that they would vote actually did vote; $51.6 \%$ accuracy since accurate prediction for this response option entailed actually casting a vote). A logistic regression shows that the interaction between vote history and predictions on accuracy is statistically significant (odds ratio $=.063, \mathrm{p}<.001)$

To compare the explanatory power of the turnout self-prediction question to that of vote history we used a series of ordinary least squares models with age and gender as additional covariates. Including self-predicted likelihood alone explained $16.0 \%$ of variance whereas including past vote history alone explained $20.1 \%$ of variance. The model with both self- 
prediction and past vote history explained $24.9 \%$ of the variance. ${ }^{7}$ As a point of comparison, an ordinary least squares model with age and gender as covariates that only included respondents' self-reported recollection of whether they voted in the April election explained $16.0 \%$ of variance - it was just as good a predictor of future turnout as self-prediction of future turnout.

Figure 3. Study 3 Respondents Are More Accurate When Predicting Past-Consistent Behavior

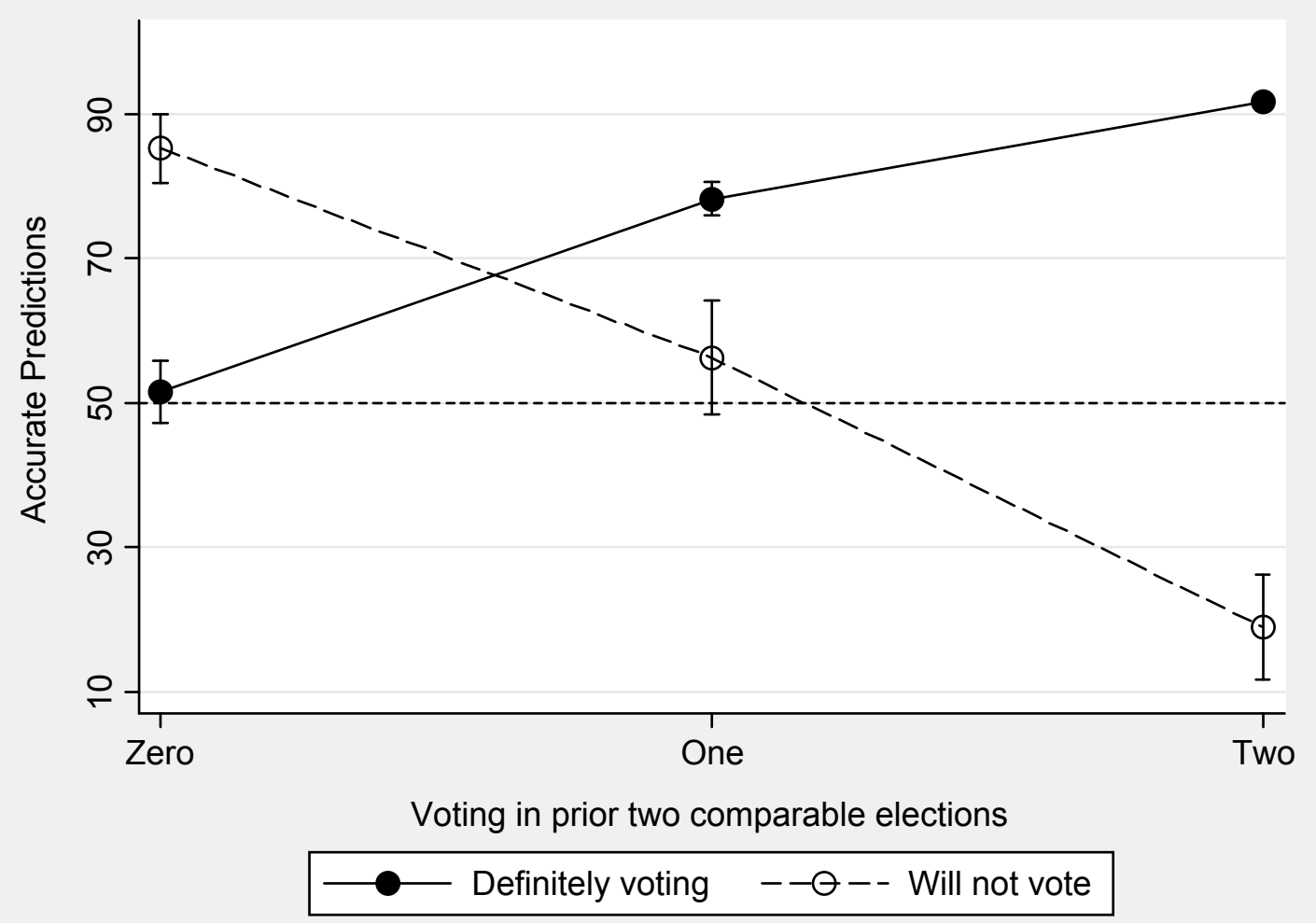

Accuracy refers to the percentage of respondents who actually voted after predicting "definitely voting" (solid line) and who did not vote after predicting "will not vote" (dashed line). Error bars indicate $95 \%$ confidence interval.

\footnotetext{
${ }^{7}$ Entering each level of response to the self-prediction question as a dummy variable instead of as a continuous variable does not substantially change the results: including self-predicted likelihood alone explained $16.7 \%$ of variance whereas including past vote history alone explained $20.2 \%$ of variance. The model with both selfprediction and past vote history explained $25.2 \%$ of the variance.
} 


\section{Discussion}

Study 3 rules out two possible memory-based explanations for the pattern of inaccurate self-prediction found in each of the studies in this manuscript. First, it shows that respondent inaccuracy at predicting future voting behavior is not because of a lack of introspective access to information in memory that would enhance predictive accuracy (i.e., past vote history). Second, it shows that respondent inaccuracy at predicting future voting behavior is not because information in memory that would enhance predictive accuracy (i.e., past vote history) is not salient when predictions are formed. This finding either means that the relevant past information is already salient when people are predicting their future voting behavior (which would be consistent with mounting evidence from psychology and neuroscience (see Schacter, Addis, and Buckner 2007), or that for this particular domain past behavior is not incorporated into predictions of future behavior. With the current data we are unable to disentangle these two possible interpretations. At the same time, these results are consistent with behavioral decision research showing that people underuse relevant base-rate information when forecasting future behaviors (Kahneman and Lovallo 1993). That work argues that people make forecasts from an "inside" perspective, believing that the current extenuating circumstances make information from an "outside" perspective (ie, base-rate information) non-diagnostic.

Replicating the same patterns found in Study 1 and Study 2, Study 3 also finds that a substantial percentage of those who predicted they would not vote actually did (39.5\%). Further, a large fraction of those who predicted they would definitely vote did not (17.3\%). Also consistent with the previous two studies, accuracy was greatest when predictions were consistent with past voting behavior. 


\section{GENERAL DISCUSSION}

The vote intention questions examined in this manuscript generated surprisingly inaccurate self-predictions: many of those intending to vote, in fact, did not vote, and many of those intending to not vote, in fact, did vote. The finding that many who said they would not vote actually did vote has not been carefully observed before. This is likely because there have been few studies of validated vote, and within those studies few respondents reported intending to not vote. The errors in self-prediction observed in these studies were significantly correlated with whether or not respondents were predicting that they would behave consistently with their own past behavior. These inaccurate self-predictions do not appear to result from respondents not having access to accurate memory-based information about their past behavior, or from this information not being cognitively salient during the time predictions about future behavior are formed. In summary, these studies show that self-prediction of turnout is far inferior to past vote history as a predictor of actual turnout, despite the fact that past vote history is accessible and available to respondents when self-predicting. Moreover, self-prediction of future turnout is no better at predicting future actual turnout than self-reported recall of turnout in a single past election.

There are several implications of these findings. First, as reviewed above, these findings raise questions about the usefulness of self-reported intention to vote as a dependent variable in political science research. These findings do not altogether undermine the use of this dependent variable, but rather raise new questions. For example, given the inaccuracy of self-reported intention to vote highlighted in this manuscript, how should we interpret the meaning of a change in intention to vote, as is common in the literature described above (e.g., Ansolabehere \& Iyengar 1995; Mutz \& Reeves 2005; Hillygus 2005; Gerber \& Rogers 2009; Gerber, Huber, \& 
Washington 2010). Does it signify an increased probability of voting, a fleeting change in motivation to vote, or possibly neither? One implication of these findings for political science research is that analysis of data involving intention to vote likely should explicitly address past vote history - either by controlling for it in observational data, or by stratifying by it in experimental data. This is because past vote history is a much more powerful predictor of future turnout than self-prediction is. Across all three studies, adding self-prediction to a predictive model that includes past vote history increases variance explained by less than a quarter, whereas adding past vote history to a model that includes self-prediction more than doubles variance explained. Given that the current CCES and ANES include prospective intention to vote questions, it is likely that future research will continue to use intention to vote as a dependent variable, which makes these considerations of continuing relevance.

Second, this research has implications for voter registration policy. Recall that a large proportion of eligible voters who predicted that they would not vote actually did vote. This suggests that scheduling the deadline for voter registration in advance of an election (as all but a small number of states currently do) may reduce overall turnout. Registration in advance of an election requires that citizens anticipate their interest for casting a vote in an election, and the results we report show that people's ability to do this is limited. This is consistent with recent research suggesting that Election Day registration increases overall turnout (Knack, 2001; Highton, 2004).

Third, this research has implications for political researchers. Political pollsters commonly screen who is eligible to participate in their surveys by including only those who report being "absolutely certain to vote" or "very likely going to vote." The present research 
suggests that this screen question is grossly inadequate for defining the "likely electorate." ${ }^{\circ}$ One approach we suggest is using a combination of self-report and voter file data. For example, the present data suggests that when calling from a list of registered voters a hybrid approach incorporating both vote history and self-report could substantially increase accuracy when predicting who will vote and who will note. Accounting for other variables, such as demographic characteristics available on voter files, could make this strategy even more effective. Additionally, our research has immediate implications for practitioners involved in campaign activities that use self-reported intention to vote as a screen for whether or not to target citizens with persuasive communications and/or get-out-the-vote contact.

What contributes to the fact that such a large proportion of respondents who predicted that they would not vote actually did vote? Study 3 rules out the memory-based hypotheses that respondents do not have access to accurate past vote history information, and that past vote history is not salient when predictions are being formed. We describe and assess several other potential hypotheses. First, it is possible that when asked to self-predict in a moment that is temporally distant from Election Day that respondents genuinely were not able to predict whether or not they would vote (e.g., perhaps because of a failure to anticipate the energy and excitement as Election Day neared). This would suggest that self-prediction should become more accurate as the prediction is made nearer to Election Day. Study 1 suggests that this was not the case.

Second, it is conceivable that respondents expected that reporting that they would not vote would result in termination of the interview and so they strategically offered that response to

\footnotetext{
${ }^{8}$ Since these surveys do not include interviews from those who said they would not vote but actually did vote, we are not able to determine here how different the preferences of actual voters were from those who self-predicted that they would vote.
} 
politely get off the phone. If this were the case we might expect that in Study 1, among the four response options available, there would be an especially high actual turnout rate among those who reported that they "will not vote" relative to those who reported that they had a "50-50 chance" of voting. This was not the case, and Table 2 shows that turnout rate increases virtually linearly with each level of response option.

Third, it is possible that respondents failed to appreciate the social and informational experience before and on Election Day when they predicted whether or not they would vote. By failing to account for the additional motivation aroused by the excitement of others, they may have underestimated the motivation to vote they would feel when it came time to actually vote. For example, when self-predicting whether or not they would vote at a moment days before the time to actually vote, respondents may not have been aware that many of their friends and family were going to vote, and therefore failed to anticipate the resulting social influence (Gerber and Rogers 2009). If this explanation is true, relatively high profile elections with high energy around Election Day and substantial spending at the end of the campaign should show higher rates of turnout among those who self-predict not voting than elections with relatively lower energy and profile. Consistent with this hypothesis, we found that the turnout rate among those who self-predicted that they would not vote in the high salience election in Study 1 (54\%) was greater than the turnout rate among those who self-predicted that they would not vote in the lower salience elections studied in Study 2 (36\%) and Study $3(39.5 \%)$. We do note, though, the limited validity of comparing just these three studies because they involved different voting likelihood questions, and were conducted at different times in their respective election cycles. We hope future research will test this hypothesis directly. 
Fourth, given that the respondents who reported intending to not vote but actually did vote were disproportionately regular voters, it is possible that these respondents offered answers meant to convey disaffection toward the political process rather than sincere lack of intention to vote. This would be consistent with research suggesting that many voters are disaffected with politics, and that this feeling is unrelated to political participation tendencies (Pinkleton, Austin and Fortman 1998). Future research could further examine this hypothesis in validated vote surveys by asking questions after the self-reported intention to vote question about respondents' feelings towards politics.

Fifth, it is possible that respondents genuinely offered their best predictions about whether or not they would vote, and that they are simply poor predictors. The present data does not allow us to further assess this possibility, but it is conceivable and consistent with psychological research on the limits of behavioral prediction. Interestingly, Study 3 shows that respondents have access to information that would be highly predictive of whether or not they would vote (i.e., their past behavior). For reasons we do not understand, respondents seem to not correctly access or weight that information when predicting whether or not they will vote. We look forward to further research on this topic as well. 


\section{References}

Ajzen, I. (1991). The theory of planned behavior. Organizational Behavior and Human Decision Processes, 50, 179-211.

Merkle, D. M., \& Edelman, M. (2002). Nonresponse in exit polls: A comprehensive analysis. In R. M. Groves, D. A. Dillman, J. L. Eltinge, \& R. J. A. Little (Eds.), Survey nonresponse (pp. 243-275). New York: John Wiley and Sons.

Ansolabehere, S., \& Iyengar, S. (1995). Going negative: How political advertisements shrink and polarize the electorate. New York: Free Press.

Ansolabehere, S., Iyengar, S., \& Simon, A. (1999). Replicating experiments using aggregate and survey data: The case of negative advertising and turnout. The American Political Science Review, 93, 901-909.

Brooks, D. J. (2006). The resilient voter: Moving toward closure in the debate over negative campaigning and turnout. The Journal of Politics, 68, 684-96.

Dimock, M., Keeter, S., Schulman, M. \& Miller, C. (2001). Screening for likely voters in preelection surveys. Paper presented at the annual meeting of the American Association for Public Opinion Research, Montreal, Canada.

Epley, N., \& Dunning, D. (2000). Feeling holier than thou: Are self-serving assessments produced by errors in self- or social prediction? Journal of Personality and Social Psychology, 79, 861-875.

Fast, N. J., Gruenfeld, D. H., Sivanathan, N., \& Galinsky, A. D. (2009). Illusory control: A generative force behind power's far-reaching effects. Psychological Science, 20, 502508. 
Freedman, P., \& Goldstein, K. (1996). Building a probable electorate from preelection polls: A two-stage approach. Public Opinion Quarterly, 60, 574-587.

Gerber, A. S., Huber, G., \& Washington, E. (2010). Party affiliation, partisanship, and political beliefs: A field experiment. The American Political Science Review, 104, 720-744.

Gerber, A. S., \& Rogers, T., (2009). Descriptive social norms and motivation to vote: everybody's voting and so should you. The Journal of Politics, 71, 178-191.

Highton, B. (2004). Voter registration and turnout in the United States. Perspectives on Politics, 2, 507-515.

Hillygus, S. D. (2005). Campaign effects and the dynamics of turnout intention in Election 2000. The Journal of Politics, 67, 50-68.

Kahneman, D., \& Lovallo, D. (1993). Timid choices and bold forecasts: A cognitive perspective on risk taking. Management Science, 39, 17-31.

Knack, S. (2001). Election Day registration: The second wave. American Politics Research, 29, 65-78.

Mann, C. (2003). Actions speak louder than words: Are vote likelihood screens effective? Paper presented at the 2003 Annual Conference of the American Association for Public Opinion Research, Nashville, TN.

Murray, G., Riley, C., \& Scime, A. (2009). Pre-election polling: Identifying likely voters using iterative expert data mining. Public Opinion Quarterly, 73, 159-171.

Mutz, D. C., \& Reeves, B. (2005). The new videomalaise: Effects of televised incivility on political trust. The American Political Science Review, 99, 1-16.

Ouellette, J. A., \& Wood, W. (1998). Habit and intention in everyday life: the multiple processes by which past behavior predicts future behavior. Psychological Bulletin, 124, 54-74. 
Perry, P. (1960). Election survey procedures of the Gallup poll. Public Opinion Quarterly, 24, $531-42$.

Perry, P. (1979). Certain problems in election survey methodology. Public Opinion Quarterly, $43,312-325$.

Pinkleton, B. E., Austin, E. W., \& Fortman, K. J. (1998). Relationships of media use and political disaffection to political efficacy and voting behavior. Journal of Broadcasting and Electronic Media, 42, 34-49.

Schacter, D. L. (1999). The seven sins of memory: Insights from psychology and cognitive neuroscience. American Psychologist, 54, 182-203.

Schacter, D. L., Addis, D. R., \& Buckner, R. L. (2007). Remembering the past to imagine the future: The prospective brain. Nature Reviews Neuroscience, 8, 657-661.

Silver, B. D., Abramson, P. R., \& Anderson, B. A. (1986). The presence of others and overreporting of voting in American national elections. Public Opinion Quarterly, 50, $228-39$.

Silver, B. D., Abramson, P. R., \& Anderson, B. A. (1986). Who overreports voting? American Political Science Review, 80, 613-624.

Snyder, M. (1974). Self-monitoring of expressive behavior. Journal of Personality and Social Psychology, 30, 526-537.

Tourangeau, R., Rips, L. J., \& Rasinski, K.A. (2000). The psychology of survey response. Cambridge, England: Cambridge University Press.

Triandis, H. C. (1977). Interpersonal behavior. Monterey, CA: Brooks/Cole. 